\title{
Mts1 Up-regulation is Associated With Aggressive Pathological Features in Thyroid Cancer
}

\author{
MIN GYEONG CHEON ${ }^{*}$, YE WON SON ${ }^{1 *}$, JOON-HYOP LEE ${ }^{2}$, HO HEE JANG ${ }^{1}$ and YOO SEUNG CHUNG ${ }^{2}$ \\ ${ }^{1}$ Department of Biochemistry, College of Medicine, Gachon University, Incheon, Republic of Korea; \\ ${ }^{2}$ Department of Surgery, Gil Medical Center, Gachon University College of Medicine, Incheon, Republic of Korea
}

\begin{abstract}
Background/Aim: Thyroid cancer is the most common type of endocrine cancer and its incidence and mortality are increasing. However, few studies on the molecular factors related to its poor prognosis have been performed. The aim of our study was to identify a poor prognostic factor for thyroid cancer to reduce its overtreatment, recurrence, and mortality. Materials and Methods: The present study is a retrospective study of 55 patients who were diagnosed with papillary thyroid cancer and operated in Korea from September 2013 to November 2015. Results: Mts1 is a member of the $\$ 100$ protein family and is involved in tumor progression and metastasis. Mts 1 was highly expressed in patients with thyroid cancer and high Mts1 levels were related to poor prognoses such as lymph node metastasis. Conclusion: Mts 1 is associated with aggressive pathological features in thyroid cancer, and may be a poor prognostic factor for thyroid cancer.
\end{abstract}

Thyroid cancer is the most common endocrine-related cancer in the USA and the incidence of thyroid cancer has increased. According to SEER (Surveillance, Epidemiology, and End Results Program) data, rates for new thyroid cancer cases have been rising by an average of $3.1 \%$ each year over the last decade (1). In Korea, thyroid cancer is the third most common carcinoma, among all kinds of cancer, with an

This article is freely accessible online.

*These Authors contributed equally to this work

Correspondence to: Ho Hee Jang, Department of Biochemistry, College of Medicine, Gachon University, Incheon 21999, Republic of Korea. Tel: +82 328996317, Fax: +82 328996318, e-mail: hhjang@gachon.ac.kr; Yoo Seung Chung, Department of Surgery, Gil Medical Center, Gachon University College of Medicine, Incheon 21565, Republic of Korea. Tel: +82 324603244, Fax: +82 324603247, e-mail: dryooseung@gilhospital.com

Key Words: Mts1, thyroid cancer, endocrine cancer, prognostic factor. incidence rate of $11.7 \%$ in 2015 (2). The first choice of treatment for thyroid cancer is surgery, followed by radioactive iodine therapy. In early thyroid cancer, hemithyroidectomy is suitable. The prognosis for thyroid cancer is excellent and the 5-year survival rate is over $98 \%$ in USA and Korea $(1,2)$. This good prognosis has been reported to be due to overtreatment of papillary thyroid microcarcinoma (PTMC), which is less than $1 \mathrm{~cm}$. Diagnosis of small-sized cancers among all thyroid cancers has increased, and about $70 \%$ of the cancers now appear as $1-\mathrm{cm}$ or smaller cancers. However, the incidence of advanced thyroid cancer, as well as PTMC, has been increasing, and the mortality rate from thyroid cancer has increased by an average of $0.7 \%$ each year from 2006 to 2015. In the case of distant metastasis, the 5-year survival rate decreases to $55.5 \%$ in SEER data and $71.0 \%$ in Korea $(1,2)$. Furthermore, in thyroid cancer, recurrence is a more important problem than mortality. The recurrence rate is high, ranging from $1.4 \%$ to $35 \%$ (3-5), and re-operation or systemic therapy with radioactive iodine must be performed in these cases. Even PTMC has been reported to recur, form distant metastasis, and cause death in some cases $(6,7)$. Although recurrence and mortality also occurred in thyroid cancer patients, the molecular biological factors associated with poor prognosis are not clear. Preoperative knowledge of molecular biological factors for poor prognosis prevents repetitive operations and radioactive therapy and reduces recurrence rates and mortality. It may also reduce overtreatment of thyroid cancer.

Mts1, also known as S100A4, is a polypeptide of 101 amino acids belonging to the $\mathrm{S} 100$ protein family. $\mathrm{S} 100$ proteins are $\mathrm{Ca}^{2+}$-binding proteins with a low molecular mass (10 to $12 \mathrm{kDa}$ ) (8-10). Mts1 has been shown to be associated with tumor progression and metastasis $(8,10,11)$, by activating and integrating both intracellular and extracellular pathways to induce cancer metastasis $(9,11)$. In thyroid cancer, Mts1 has been related to poor prognosis, invasion, and metastasis in several studies (12-18). However, research using clinical and pathological data of thyroid cancer patients has not been performed yet. Therefore, Mts1 expression in thyroid cancer and 
the association between Mts1 and clinicopathological features of thyroid cancer were evaluated. Our results demonstrated that high levels of Mts1 in patients with thyroid cancer were associated with poor prognoses.

\section{Materials and Methods}

Protein-protein interaction (PPI) network analysis. Search Tool for the Retrieval of Interacting Genes (STRING 10.5, https://stringdb.org/) and Gene Multiple Association Network Integration Algorithm (GeneMANIA, http://genemania.org/) database tools were used to analyze gene-gene interactions and gene functions associated with Mts1. PPIs of STRING analysis was based on experimental and text mining only, and an interaction score of $\geq 0.7$ was used as the cut-off value (highest $\geq 0.9$, high $\geq 0.7$, medium $\geq 0.4$, low confidence $\geq 0.15$ ).

Gene expression profile data. Mts1 expression profile data of various normal tissues (GDS3113) and normal versus anaplastic thyroid cancer (GDS5362) were obtained from Gene Expression Omnibus (GEO, https://www.ncbi.nlm.nih.gov/geo/).

Patients \& methods. The present study is a retrospective study of patients with thyroid cancer. The study population consisted of 55 subjects who had been diagnosed with papillary thyroid cancer (PTC) and operated on from September 2013 to November 2015 at Gachon University Gil Medical Center in Korea. Medical records, pathology reports, and operation records suggestive of prognostic factors were retrospectively evaluated. The staging of these thyroid cancers was classified according to the American Joint Committee on Cancer classification (AJCC, 8th edition). For this study, patients who had been experienced recurrence of thyroid cancer were excluded. This study was approved by the Institutional Ethical Committee and Review Board of the Gachon University Gil Medical Center (IRB No. GAIRB2015-122).

Western blot analysis. Tissue samples were lysed in lysis buffer (20 mM HEPES pH 7.5, $150 \mathrm{mM} \mathrm{NaCl}, 10 \%$ glycerol, $1 \%$ Triton $\mathrm{X}-100$, and $5 \mathrm{mM}$ EDTA) supplemented with protease inhibitor cocktail (GeneDEPOT, Katy, TX, USA) on ice for $15 \mathrm{~min}$. Cell lysates were centrifuged at $12,000 \mathrm{rpm}$ at $4{ }^{\circ} \mathrm{C}$ for $15 \mathrm{~min}$. Protein concentration in the supernatants was measured by the Bradford assay (Bio-Rad, Hercules, CA, USA). The lysates were separated on $10 \%$ SDS-polyacrylamide gels and transferred onto a nitrocellulose membrane (Millipore, Burlington, MA, USA). The antibodies used for Western blots were as follow: Mts1 (A5114, Dako, Via Real Carpinteria, CA, USA), GAPDH (sc-47724, Santa Cruz, Dallas, TX, USA).

Immunohistochemistry. The expression of Mts1 in human thyroid cancer tissues and matching adjacent normal thyroid tissues was examined by immunohistochemistry. After embedding in paraffin, tissue sections were de-paraffinized in xylene and dehydrated in a progressively decreasing ethanol series and incubated in $10 \mathrm{mM}$ sodium citrate buffer, $\mathrm{pH} 6.0$ in a microwave oven for $20 \mathrm{~min}$. After inactivation of the endogenous peroxidase activity with $3 \%$ hydrogen peroxide at room temperature for $5 \mathrm{~min}$, the sections were blocked with $1 \%$ normal horse serum for $30 \mathrm{~min}$, and incubated with primary Mts1 antibody (1:200) overnight at $4^{\circ} \mathrm{C}$. The sections were washed with phosphate buffered saline (PBS) three times, and incubated with biotinylated secondary antibody at room temperature for $30 \mathrm{~min}$, and visualized with 3,3'-diaminobenzidine hydrochloride (DAB) (VECTOR laboratories, Burlingame, CA, USA). Finally, the sections were counterstained with hematoxylin (VECTOR laboratories), and photographs were taken using a microscope with a digital camera.

Statistical analysis. Statistical analyses were performed using IBM SPSS version 23.0. Pearson's $\chi^{2}$ test, Fisher's exact test, and independent $t$ tests were used to evaluate the significance of the relationship between Mts1 and thyroid cancer. Logistic regression analysis was performed for multivariate analysis. The $p$-values less than 0.05 were considered statistically significant.

\section{Results}

Mts1 associated with a variety of cancer-related pathways. Since Mts1 is closely related to tumor progression and metastasis, database tools were used to investigate cancerrelated signaling pathways associated with Mts1 in various cancers. The protein-protein interaction (PPI) network associated with the Mts1 protein was analyzed using Gene Multiple Association Network Integration Algorithm (GeneMANIA) and Search Tool for the Retrieval of Interacting Genes/Proteins (STRING) database tools. Mts 1 is involved in tumorigenesis through regulation of apoptosis, cell cycle, DNA damage checkpoint and focal adhesion signaling pathway by physical interactions or coexpression etc., with TP53, AKT1, Raf family and MAPKs (Figure 1A left). GeneMANIA analysis also indicated that Mts 1 is associated with a variety of growth factors, such as EGF, EGFR, and TGF $\beta$ and that it is also involved in EMT, cell growth and proliferation (Figure 1A right). Similarly, the STRING database revealed that Mts1 forms three cluster networks, according to functional classification through 28 nodes (genes) and 84 edges (interactions) (PPI enrichment $p<0.001)$. The first red cluster includes genes involved in apoptosis signaling pathways, cell cycle progression, and tumorigenesis. The second green cluster is associated with snRNP assembly pathway and the blue is undefined. Among the clusters, genes with the highest degree of association as functional partners with Mts1 are summarized in the Figure 1B right. CDH1 and TP53 are well-known genes that are closely related to tumorigenesis (19-22). CDH1, a key component of EMT, was negatively associated with Mts 1 at the transcription level (interaction score: 0.777$)(23,24)$. Moreover, the stability of tumor protein p53 was regulated through interaction with Mts1 (interaction score: 0.787) (Figure 1B) $(25,26)$. These data suggest that Mts1 could regulate tumor progression, metastasis, and poor prognosis through a variety of cancerrelated pathways, as mentioned in previous studies. However, it is unclear whether Mts1 promotes tumor progression in patients with cancer because few studies 

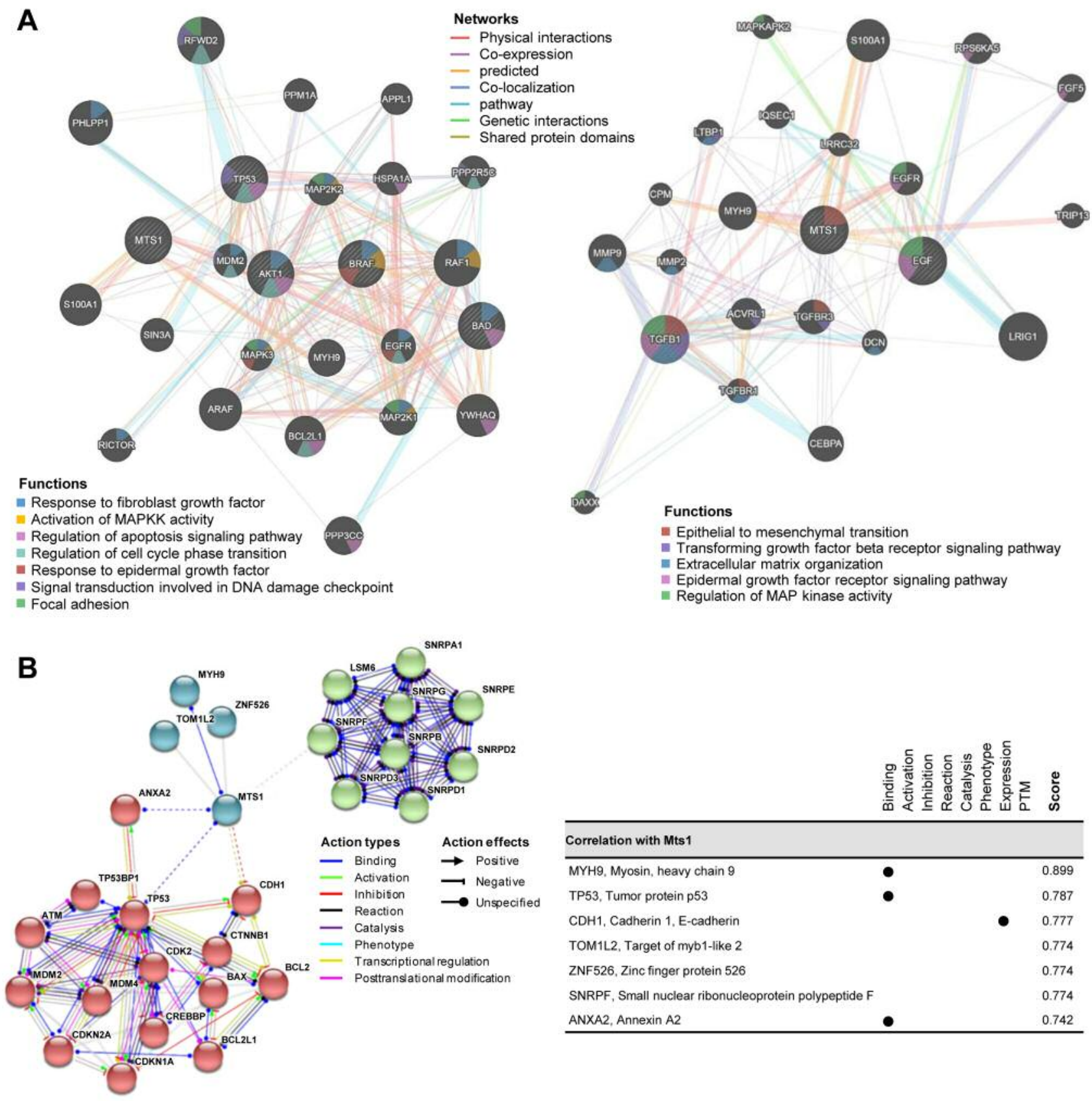

Figure 1. Analysis of protein-protein interaction (PPI) networks associated with Mts1. PPI networks analysis related to Mts1 by GeneMANIA (A) and String 10.5 (interaction score; highest $\geq 0.9$, high $\geq 0.7$, medium $\geq 0.4$, low confidence $\geq 0.15$ ) (B) database tools.

have been performed in patients using clinical and pathological data, especially in patients with thyroid cancer. In addition, there have been some reports that up-regulation of Mts1 expression is associated with tumorigenesis. Thus, the expression of Mts1 in human tissues, including thyroid cancer was examined to determine the function of Mts1 in patients with cancers.
Mts1 is highly expressed in thyroid cancer. Microarray-based RNA profiling analysis using the Gene Expression Omnibus (GEO) datasets showed that the expression levels of Mts1 in the thyroid were relatively low compared to other normal human tissues (Figure 2A). However, the expression levels of Mts1 were largely increased in anaplastic thyroid cancer compared to normal thyroid tissue (Figure 2B). These results 
A

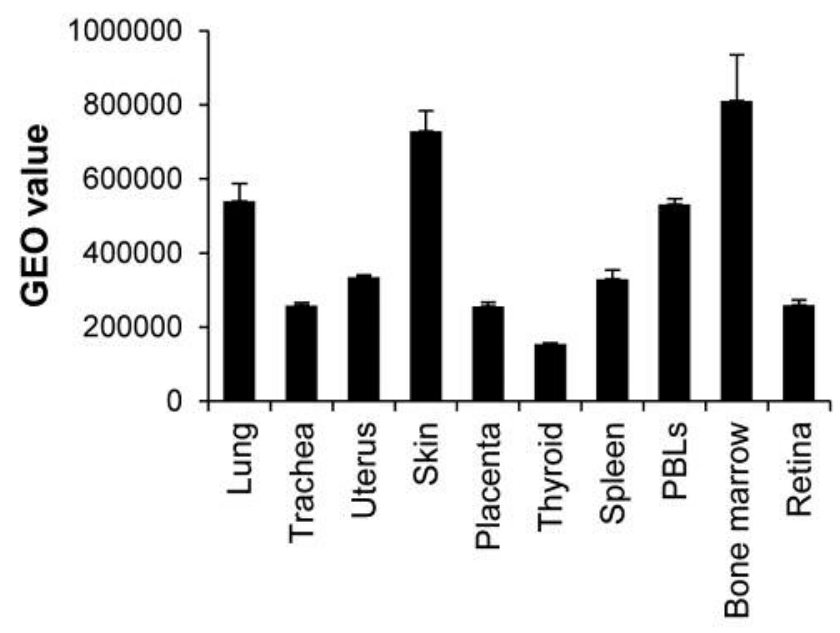

B

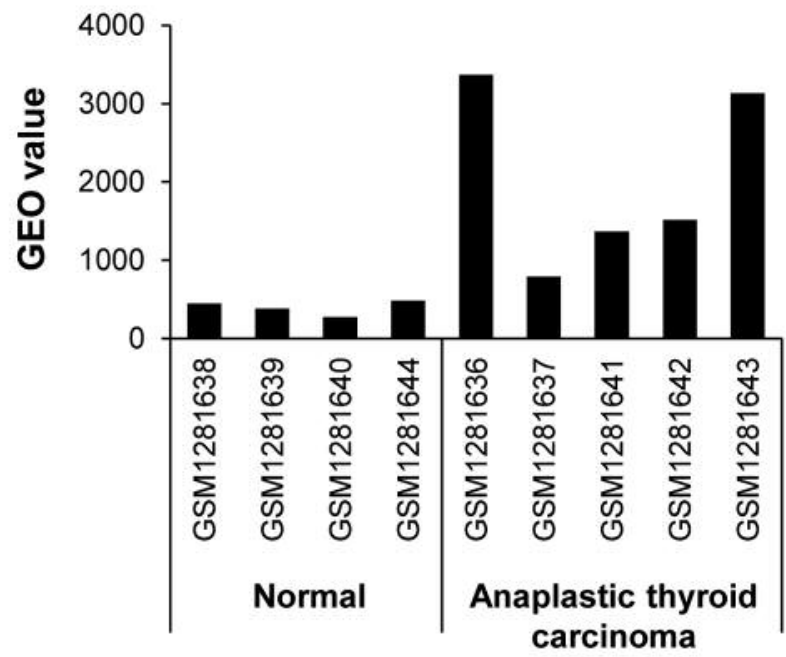

Figure 2. Mts1 expression using GEO databases. The NCBI Gene Expression Omnibus (GEO) data sets were utilized for profiling the expression of Mts1 in various human tissues (A), and in normal thyroid and anaplastic thyroid tissues $(B)$.

prompted us to investigate the clinical and pathological effects of Mts1 in the tumorigenesis of thyroid cancer.

To explore the relationship between the expression levels of Mts 1 and tumorigenesis of thyroid cancer, we examined the expression levels of Mts1 in 55 pairs of Korean thyroid cancer patients (tumor $v s$. adjacent non-tumors) from 2013 to 2015. Expression levels of Mts 1 in 16 thyroid cancer patients were analyzed by immunoblotting (Figure 3A). Quantification of Mts1 expression levels in adjacent nontumor and thyroid cancer tissues revealed that the average expression of Mts1 in thyroid cancer was significantly higher than in adjacent non-tumor (12229 $\pm 1195 v s$. 4471 \pm 615.5 ; $p<0.0001$ ) (Figure 3B). As described above, Mts1 showed high expression in thyroid cancer. However, to determine the relative expression of Mts1 in tumor tissue $v s$. adjacent non-tumor tissue in more detail, the tissue pairs were analyzed again. Expression of Mts1 was $76.4 \%$ higher in tumor tissues than in adjacent non-tumor tissues. The highest level of Mts1 in thyroid cancer tissue was about 12 times higher than that of non-tumors. In contrast, the ratio of high Mts 1 in adjacent non-tumor tissues was only $23.6 \%$ compared to tumor tissues (Figure 3C). Histological analysis showed that normal thyroid tissue displays follicles lined by epithelium, containing homogenous, acidophilic materials called colloid (upper, left, $H \& E \times 10$ ), while a case of PTC displayed papillary structure and nuclei changes such as nuclear elongation, chromatin clearing, and longitudinal grooves (lower, left, $H \& E \times 10$ ). Also, weak cytoplasmic staining of thyroid follicular cells was observed in normal thyroid tissue (upper, middle and right,
IHC $\times 10$ ) and cytoplasmic membrane and the nuclei in some tumor cells were strongly immunoreactive for Mts1 (lower, middle and right, IHC $\times 10$ ) consistent with the immunoblotting data of Mts1 (Figure 3D). Overall, these results showed that Mts1 was up-regulated in thyroid cancer. These findings indicated that high levels of Mts 1 are associated with thyroid cancer.

Up-regulation of Mts1 expression correlates with clinicopathologic features of thyroid cancer. Next, to investigate the implication of Mts 1 expression in patients with thyroid cancer, the clinical characteristics of 55 patients were analyzed. Analysis of the expression of Mts1 and clinicopathologic factors showed that patients' age at diagnosis, extrathyroidal extension (ETE), and lymph node metastasis (LNM) were correlated with high expression of Mts1. Patients with high expression of Mts1 were younger than the other group and there were more patients of less than 55 years. They showed more ETE, LNM, and advanced $\mathrm{N}$ stage. In multivariate analysis, younger age, and LNM were significantly associated with high expression of Mts1. Consequently, high levels of Mts1 were associated with poor prognosis in patients with thyroid cancer (Table I). These results suggested that overexpression of Mts 1 in patients with thyroid cancer leads more aggressive pathological features such as LNM.

Altogether, our clinical and pathological data and online database results suggest that Mts1 may be a poor prognostic factor and a promising molecular biological factor that may help reduce recurrence rates and mortality. 
A

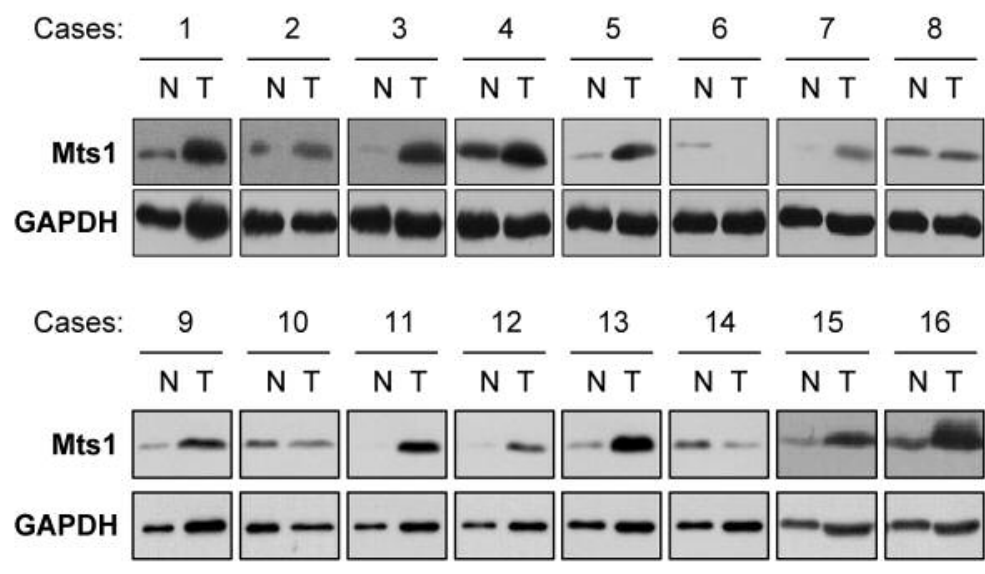

B

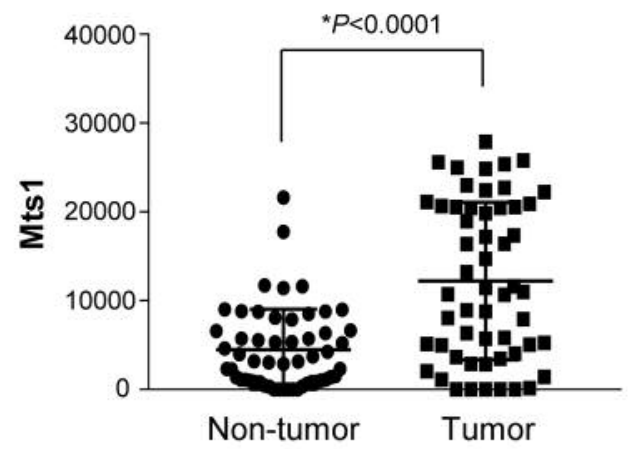

C

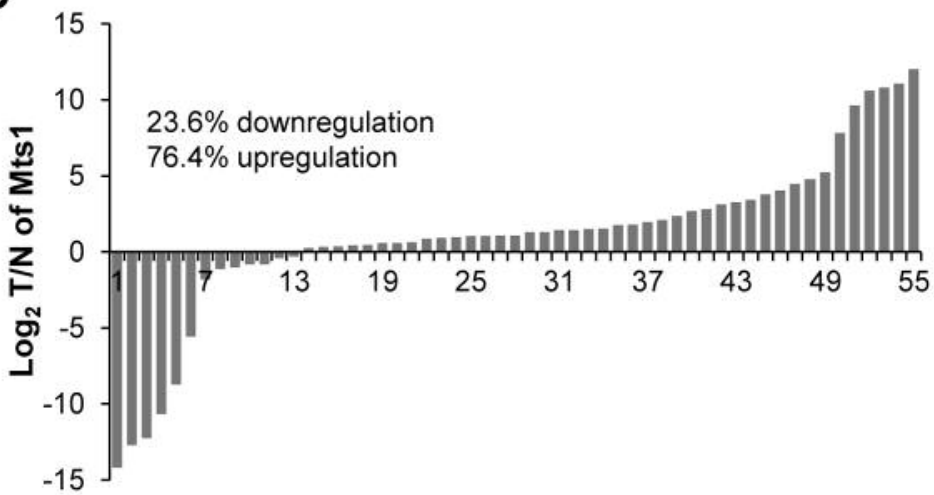

D

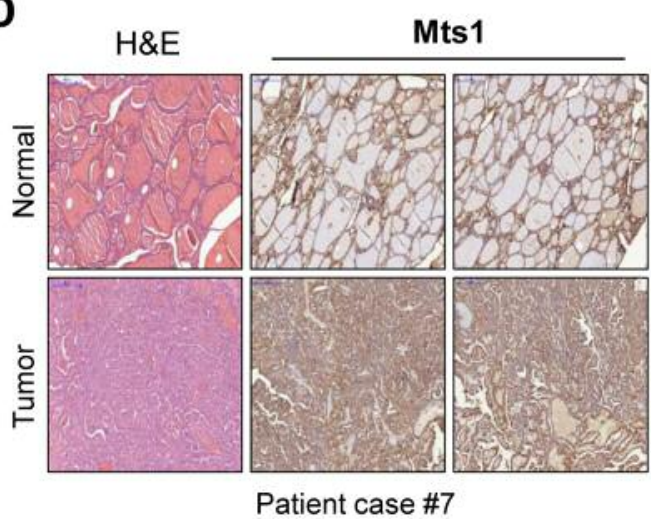

Figure 3. Mts1 expression in patients with thyroid cancer. (A) Western blot analysis of Mts1 expression in adjacent non-tumor (N) and tumor (T) tissues from patients with thyroid cancer. (B) Mts1 average expression measured in 55 pairs of thyroid cancer tissues. $\left({ }^{*} p<0.0001\right)$. (C) Relative expression of Mts1 in tumors normalized to adjacent non-tumor tissues (T/N fold change). (D) Representative immunohistochemistry images of Mts 1 in a thyroid cancer patient (\#7).

\section{Discussion}

ETE and LNM are associated with disease recurrence and persistence of thyroid cancer. N stage, a part of AJCC TNM cancer staging manual, is correlated with disease-related survival (27). Since high expression of Mts1 was correlated with ETE, LNM, and $\mathrm{N}$ stage, Mts1 could be a factor indicating disease recurrence, persistence, and disease-related survival. Furthermore, in multivariate analysis, patients with high expression of Mts1 showed significantly more LNM. In a study of a murine model of thyroid cancer, Mts1 was related to advanced cases and LNM. Analysis of primary tumors and their matched LNM in humans demonstrated that significantly higher Mts1 transcripts were present in metastatic tumors compared to the primary tumors. This suggested that overexpression of Mts1 is associated with thyroid tumor invasion and metastasis $(13,16)$. Interestingly,
Mts1 was detected even in PTMC, less than $1 \mathrm{~cm}$ sized PTC. This suggested that Mts1 plays a constitutive role in PTC and it may be a useful marker for early detection of PTC (28). In another study of PTMC, Mts1 was related to LNM. On multivariate analysis, expression of Mts1 was found to be an independent predictive factor of LNM, macro-metastases, and lateral node metastasis (17). In our study, tumor size was smaller and the proportion of microcarcinoma was higher in the high expression group, though not statistically significant. PTMC usually has an excellent long-term prognosis, but it can metastasize to neck lymph nodes and distant organs (29). Mts1 might be associated with tumor invasion and metastasis in small thyroid cancer.

Age at diagnosis of thyroid cancer is an independent predictor of disease-specific survival in the staging system. Most of the other clinicopathological staging systems use an age cut-off between 40 and 55 years, or age as a continuous 
Table I. Association between Mts1 expression and clinical characteristics of patients with thyroid cancer.

\begin{tabular}{|c|c|c|c|c|c|}
\hline \multirow[t]{2}{*}{ Variable } & \multicolumn{2}{|c|}{ Mts1 (\%) } & \multirow{2}{*}{$\begin{array}{c}\text { Univariate analysis } \\
p \text {-Value }\end{array}$} & \multicolumn{2}{|c|}{ Multivariate analysis } \\
\hline & Low $n=12$ & High $n=43$ & & HR $(95 \% \mathrm{CI})$ & $p$-Value \\
\hline \multicolumn{6}{|l|}{ Gender } \\
\hline Female & $9(75.0 \%)$ & $32(74.4 \%)$ & $\mathrm{n} . \mathrm{s}$ & & \\
\hline Male & $3(25.0 \%)$ & $11(25.6 \%)$ & & & \\
\hline AGE & $57.17 \pm 15.33$ & $46.67 \pm 12.10$ & 0.015 & $0.902(0.822-0.989)$ & 0.029 \\
\hline$<55$ & $4(33.3 \%)$ & $33(76.7 \%)$ & 0.012 & & $\mathrm{n} . \mathrm{s}$ \\
\hline$\geq 55$ & $8(66.7 \%)$ & $10(23.3 \%)$ & & & \\
\hline SIZE & $2.68 \pm 1.98$ & $1.54 \pm 0.83$ & $\mathrm{n} . \mathrm{s}$ & & \\
\hline$\leq 1.00$ & $3(25.0 \%)$ & $13(30.2 \%)$ & n.s & & \\
\hline$>1.00$ & $9(75.0 \%)$ & $30(69.8 \%)$ & & & \\
\hline \multicolumn{6}{|l|}{ ETE } \\
\hline No & $8(66.7 \%)$ & $11(25.6 \%)$ & 0.015 & & $\mathrm{n} . \mathrm{s}$ \\
\hline Yes & $4(33.3 \%)$ & $32(74.4 \%)$ & & & \\
\hline \multicolumn{6}{|l|}{ LVI } \\
\hline No & $10(83.3 \%)$ & $31(72.1 \%)$ & n.s & & \\
\hline Yes & $2(16.7 \%)$ & $12(27.9 \%)$ & & & \\
\hline \multicolumn{6}{|l|}{ LNM } \\
\hline No & $10(83.3 \%)$ & $20(46.5 \%)$ & 0.046 & $36.843(1.283-1058.007)$ & 0.035 \\
\hline Yes & $2(16.7 \%)$ & $23(53.5 \%)$ & & & \\
\hline \multicolumn{6}{|l|}{ T stage } \\
\hline 1 & $6(50.0 \%)$ & $31(72.1 \%)$ & $\mathrm{n} . \mathrm{s}$ & & \\
\hline 2 & $3(25.0 \%)$ & $6(14.0 \%)$ & & & \\
\hline 3 & $3(25.0 \%)$ & $4(9.3 \%)$ & & & \\
\hline 4 & $0(0.0 \%)$ & $2(4.7 \%)$ & & & \\
\hline \multicolumn{6}{|l|}{$\mathrm{N}$ stage } \\
\hline 0 & $10(83.3 \%)$ & $20(46.5 \%)$ & 0.041 & & $\mathrm{n} . \mathrm{s}$ \\
\hline $1 \mathrm{a}$ & $1(8.3 \%)$ & $20(46.5 \%)$ & & & \\
\hline $1 \mathrm{~b}$ & $1(8.3 \%)$ & $3(7.0 \%)$ & & & \\
\hline \multicolumn{6}{|l|}{ M } \\
\hline 0 & $12(100.0 \%)$ & $42(97.7 \%)$ & n.s & & \\
\hline 1 & $0(0.0 \%)$ & $1(2.3 \%)$ & & & \\
\hline \multicolumn{6}{|l|}{ Stage } \\
\hline I & $9(75.0 \%)$ & $36(83.7 \%)$ & n.s & & \\
\hline II & $3(25.0 \%)$ & $5(11.6 \%)$ & & & \\
\hline III & $0(0.0 \%)$ & $1(2.3 \%)$ & & & \\
\hline IV & $0(0.0 \%)$ & $1(2.3 \%)$ & & & \\
\hline
\end{tabular}

ETE: Extrathyroidal extension; LVI: lymphovascular invasion; LNM: lymph node metastasis.

variable. The AJCC 8th TNM cancer staging manual uses 55 years as a cut-off. Disease specific survival is better in younger patients. Old age has also been reported to be an adverse factor in disease-free survival (30). However, advanced age was not an independent predictor of diseasefree survival (31). Thyroid cancer in children and adolescents frequently showed more extensive disease, such as large tumor, more LNM, and distant metastasis (32). In our study, the patients with high expression of Mts 1 were younger than the other group. Mts1 may be expressed and involved, particularly in young age of thyroid cancer. Overall, the higher expression of Mts1 in thyroid cancer than in normal tissue was associated with younger age and LNM. This suggests that Mts1 is associated with invasion, metastasis, and tumorigenesis of thyroid cancer.

\section{Conflicts of Interest}

There are no conflicts of interest to declare regarding this study.

\section{Authors' Contributions}

Conceptualization, M.G. Cheon, H.H. Jang and Y.S. Chung; investigation, M.G. Cheon and Y.W. Son; resources, J.H. Lee and Y.S. Chung; writing - original draft preparation, M.G. Cheon and Y.S. Chung; writing - review and editing, H.H. Jang; visualization, M.G. Cheon; supervision, H.H. Jang; funding acquisition, M.G. Cheon and Y.S. Chung.

\section{Acknowledgements}

This work was supported by the National Research Foundation of Korea (NRF) grant funded by the Korea government (MSIT) (NRF- 
2016R1C1B2010582 to Y.S.C. and NRF-2017R1A6A3A11036183 to M.G.C.), by a grant from the Gil Medical Center, Gachon University (FRD2015-17) to H.H.J., and by the National Research Foundation of Korea (NRF) and the Center for Women In Science, Engineering and Technology (WISET) Grant funded by the Ministry of Science, ICT \& Future Planning of Korea (MSIP) under the Program for Returners into R\&D to Y.W. Son.

\section{References}

1 Noone AM, Howlader N, Krapcho M, Miller D, Brest A, Yu M, Ruhl J, Tatalovich Z, Mariotto A, Lewis DR, Chen HS, Feuer EJ, Cronin KA (eds.). SEER Cancer Statistics Review, 19752015, National Cancer Institute. Bethesda, MD, https://seer. cancer.gov/csr/1975_2015/, based on November 2017 SEER data submission, posted to the SEER web site, April 2018.

2 Welfare MoHa. Annual report of cancer statistics in Korea in 2015. Korea Central Cancer Registry, National Cancer Center, Ministry of Health and Welfare, Korea, 2015.

3 Mazzaferri EL and Kloos RT: Clinical review 128: Current approaches to primary therapy for papillary and follicular thyroid cancer. J Clin Endocrinol Metab 86: 1447-1463, 2001. PMID: 11297567. DOI: 10.1210/jcem.86.4.7407

4 Durante C, Montesano T, Torlontano M, Attard M, Monzani F, Tumino S, Costante G, Meringolo D, Bruno R, Trulli F, Massa M, Maniglia A, D'Apollo R, Giacomelli L, Ronga G and Filetti S; PTC Study Group: Papillary thyroid cancer: time course of recurrences during postsurgery surveillance. J Clin Endocrinol Metab 98: 636642, 2013. PMID: 23293334. DOI: 10.1210/jc. 2012-3401

5 Zembska A, Jawiarczyk-Przybyłowska A, Wojtczak B and Bolanowski M: MicroRNA expression in the progression and aggressiveness of papillary thyroid carcinoma. Anticancer Res 39: 33-40, 2019. PMID: 30591438. DOI: 10.21873/anticanres. 13077

6 Mehanna H, Al-Maqbili T, Carter B, Martin E, Campain N, Watkinson $\mathrm{J}$, McCabe $\mathrm{C}$, Boelaert $\mathrm{K}$ and Franklyn JA: Differences in the recurrence and mortality outcomes rates of incidental and nonincidental papillary thyroid microcarcinoma: a systematic review and meta-analysis of 21329 person-years of follow-up. J Clin Endocrinol Metab 99: 2834-2843, 2014 PMID: 24828487. DOI: 10.1210/jc.2013-2118

7 Mercante G, Frasoldati A, Pedroni C, Formisano D, Renna L, Piana S, Gardini G, Valcavi R and Barbieri V: Prognostic factors affecting neck lymph node recurrence and distant metastasis in papillary microcarcinoma of the thyroid: results of a study in 445 patients. Thyroid 19: 707-716, 2009. PMID: 19348581. DOI: $10.1089 /$ thy.2008.0270

8 Boye K and Maelandsmo GM: S100A4 and metastasis: a small actor playing many roles. Am J Pathol 176: 528-535, 2010. PMID: 20019188. DOI: 10.2353/ajpath.2010.090526

9 Mishra SK, Siddique HR and Saleem M: S100A4 calcium-binding protein is key player in tumor progression and metastasis: preclinical and clinical evidence. Cancer Metastasis Rev 31: 163 172, 2012. PMID: 22109080. DOI: 10.1007/s 10555-011-9338-4

10 Garrett SC, Varney KM, Weber DJ and Bresnick AR: S100A4, a mediator of metastasis. J Biol Chem 281: 677-680, 2006. PMID: 16243835 . DOI: 10.1074/jbc.R500017200

11 Fei F, Qu J, Zhang M, Li Y and Zhang S: S100A4 in cancer progression and metastasis: A systematic review. Oncotarget 8 : 73219-73239, 2017. PMID: 29069865. DOI: 10.18632/conco target.18016
12 Zhang K, Yu M, Hao F, Dong A and Chen D: Knockdown of S100A4 blocks growth and metastasis of anaplastic thyroid cancer cells in vitro and in vivo. Cancer Biomark 17: 281-291, 2016. PMID: 27802204. DOI: $10.3233 / C B M-160640$

13 Zou M, Famulski KS, Parhar RS, Baitei E, Al-Mohanna FA, Farid NR and Shi Y: Microarray analysis of metastasisassociated gene expression profiling in a murine model of thyroid carcinoma pulmonary metastasis: identification of S100A4 (Mts1) gene overexpression as a poor prognostic marker for thyroid carcinoma. J Clin Endocrinol Metab 89: 6146-6154, 2004. PMID: 15579771. DOI: 10.1210/jc.2004-0418

14 Medapati MR, Dahlmann M, Ghavami S, Pathak KA, Lucman L, Klonisch T, Hoang-Vu C, Stein U and Hombach-Klonisch S: RAGE mediates the pro-migratory response of extracellular S100A4 in human thyroid cancer cells. Thyroid 25: 514-527, 2015. PMID: 25744544. DOI: 10.1089/thy.2014.0257

15 Radestock Y, Willing C, Kehlen A, Hoang-Vu C and HombachKlonisch S: Relaxin enhances S100A4 and promotes growth of human thyroid carcinoma cell xenografts. Mol Cancer Res 8: 494-506, 2010. PMID: 20332215. DOI: 10.1158/15417786.MCR-09-0307

16 Zou M, Al-Baradie RS, Al-Hindi H, Farid NR and Shi Y: S100A4 (Mts1) gene overexpression is associated with invasion and metastasis of papillary thyroid carcinoma. Br J Cancer 93: 12771284, 2005. PMID: 16265347. DOI: 10.1038/sj.bjc. 6602856

17 Min HS, Choe G, Kim SW, Park YJ, Park DJ, Youn YK, Park SH, Cho BY and Park SY: S100A4 expression is associated with lymph node metastasis in papillary microcarcinoma of the thyroid. Mod Pathol 21: 748-755, 2008. PMID: 18360353. DOI: 10.1038/modpathol.2008.51

18 Jia W, Gao XJ, Zhang ZD, Yang ZX and Zhang G: S100A4 silencing suppresses proliferation, angiogenesis and invasion of thyroid cancer cells through downregulation of MMP-9 and VEGF. Eur Rev Med Pharmacol Sci 17: 1495-1508, 2013. PMID: 23771538.

19 Agiostratidou G, Muros RM, Shioi J, Marambaud P and Robakis NK: The cytoplasmic sequence of E-cadherin promotes nonamyloidogenic degradation of A beta precursors. J Neurochem 96: 1182-1188, 2006. PMID: 16417575. DOI: 10.1111/j.14714159.2005.03616.x

20 Meigs TE, Fedor-Chaiken M, Kaplan DD, Brackenbury R and Casey PJ: Galpha12 and Galpha13 negatively regulate the adhesive functions of cadherin. J Biol Chem 277: 24594-24600, 2002. PMID: 11976333. DOI: 10.1074/jbc.M201984200

21 Kern SE, Kinzler KW, Bruskin A, Jarosz D, Friedman P, Prives $\mathrm{C}$ and Vogelstein B: Identification of p53 as a sequence-specific DNA-binding protein. Science 252: 1708-1711, 1991. PMID: 2047879. DOI: $10.1126 /$ science 2047879

22 Matlashewski G, Lamb P, Pim D, Peacock J, Crawford L and Benchimol S: Isolation and characterization of a human p53 cDNA clone: expression of the human p53 gene. EMBO J 3: 3257-3262, 1984. PMID: 6396087. DOI: 10.1002/j.14602075.1984.tb02287.x

23 Keirsebilck A, Bonne S, Bruyneel E, Vermassen P, Lukanidin E, Mareel M and van Roy F: E-cadherin and metastasin (mts$1 / \mathrm{S} 100 \mathrm{~A} 4)$ expression levels are inversely regulated in two tumor cell families. Cancer Res 58: 4587-4591, 1998. PMID: 9788607.

24 Kustikova O, Kramerov D, Grigorian M, Berezin V, Bock E, Lukanidin E and Tulchinsky E: Fra-1 induces morphological transformation and increases in vitro invasiveness and motility 
of epithelioid adenocarcinoma cells. Mol Cell Biol 18: 70957105, 1998. PMID: 9819396. DOI: $10.1128 / \mathrm{mcb} .18 .12 .7095$

25 Orre LM, Panizza E, Kaminskyy VO, Vernet E, Graslund T, Zhivotovsky B and Lehtio J: S100A4 interacts with p53 in the nucleus and promotes p53 degradation. Oncogene 32: 55315540, 2013. PMID: 23752197. DOI: 10.1038/onc.2013.213

26 Grigorian M, Andresen S, Tulchinsky E, Kriajevska M, Carlberg C, Kruse C, Cohn M, Ambartsumian N, Christensen A, Selivanova $\mathrm{G}$ and Lukanidin E: Tumor suppressor $\mathrm{p} 53$ protein is a new target for the metastasis-associated Mts1/S100A4 protein: functional consequences of their interaction. J Biol Chem 276: 22699-22708, 2001. PMID: 11278647. DOI: 10.1074/jbc.M010231200

27 Haugen BR, Alexander EK, Bible KC, Doherty GM, Mandel SJ, Nikiforov YE, Pacini F, Randolph GW, Sawka AM, Schlumberger M, Schuff KG, Sherman SI, Sosa JA, Steward DL, Tuttle RM and Wartofsky L: 2015 American Thyroid Association Management Guidelines for adult patients with thyroid nodules and differentiated thyroid cancer: the american thyroid association guidelines task force on thyroid nodules and differentiated thyroid cancer. Thyroid 26: 1-133, 2016. PMID: 26462967. DOI: $10.1089 /$ thy.2015.0020

28 Ito Y, Yoshida H, Tomoda C, Uruno T, Miya A, Kobayashi K, Matsuzuka F, Kakudo K, Kuma K and Miyauchi A: S100A4 expression is an early event of papillary carcinoma of the thyroid. Oncology 67: 397-402, 2004. PMID: 15713996. DOI: $10.1159 / 000082924$

29 Nucera $\mathrm{C}$ and Pontecorvi A: Clinical outcome, role of BRAF(V600E), and molecular pathways in papillary thyroid microcarcinoma: Is it an indolent cancer or an early stage of papillary thyroid cancer?. Front Endocrinol (Lausanne) 3: 33, 2012. PMID: 22649416. DOI: 10.3389/fendo.2012.00033
30 Grogan RH, Kaplan SP, Cao H, Weiss RE, Degroot LJ, Simon CA, Embia OM, Angelos P, Kaplan EL and Schechter RB: A study of recurrence and death from papillary thyroid cancer with 27 years of median follow-up. Surgery 154: 1436-1446; discussion 1446-1437, 2013. PMID: 24075674. DOI: 10.1016/ j.surg,2013.07.008

31 Lang BH, Lo CY, Wong KP and Wan KY: Long-term outcomes for older patients with papillary thyroid carcinoma: should another age cutoff beyond 45 years be added?. Ann Surg Oncol 22: 446453, 2015. PMID: 25190130. DOI: 10.1245/s10434-014-4055-1

32 Hay I.D, Johnson TR, Kaggal S, Reinalda MS, Iniguez-Ariza NM, Grant CS, Pittock ST andThompson GB: Papillary thyroid carcinoma (PTC) in children and adults: comparison of initial presentation and long-term postoperative outcome in 4432 patients consecutively treated at the Mayo Clinic during eight decades (1936-2015). World J Surg 42: 329-342, 2018. PMID: 29030676. DOI: $10.1007 / \mathrm{s} 00268-017-4279-\mathrm{x}$ 